\title{
QUALIDADE DE SEMEADURA NA IMPLANTAČ̃̃O DA CULTURA DO MILHO POR TRÊS SEMEADORAS-ADUBADORAS DE PLANTIO DIRETO ${ }^{1}$
}

\author{
Sowing quality in implantation of maize crop by three no-tillage seeder-fertilizers
}

\author{
Ariston Pinto Santos 2 , Maria Cristina Cavalheiro Tourino ${ }^{3}$, Carlos Eduardo Silva Volpato ${ }^{4}$
}

\begin{abstract}
RESUMO
Com o objetivo de se avaliar três semeadoras para plantio direto de milho, montou-se um experimento em área do Departamento de Engenharia da UFLA, sob Latossolo Vermelho Distroférrico argiloso (LVdf), utilizando-se as seguintes semeadoras: S1 - Semeato SHM 11/13; S2 e S3 - John Deere RT 907, com diferentes sistemas de abertura de sulcos para deposição de adubo, deslocando-se a três velocidades $\left(5,0 ; 6,5 ; 8,0 \mathrm{~km} \mathrm{~h}^{-1}\right)$. As variáveis quantificadas foram: estande de plantas $\mathrm{m}^{-1}$, índice de velocidade de emergência de plantas; uniformidade de semeadura (duplos, aceitáveis, falhas), profundidade de semeadura, danos mecânicos e germinação das sementes. Adotou-se o delineamento estatístico de blocos casualizados, com os tratamentos dispostos em parcelas subdivididas. A uniformidade de semeadura para as semeadoras S1 e S3 (sistemas análogos para corte de palha e abertura dos sulcos de fertilizantes) foi semelhante, não sendo observadas diferenças significativas entre elas; o sistema pneumático não apresentou vantagem econômica (considerando o alto investimento) em relação ao sistema mecânico de discos horizontais, na implantação da cultura do milho; o aumento da velocidade reduziu a uniformidade de semeadura (duplos, aceitáveis e falhas) e aumentou a danificação mecânica das sementes.
\end{abstract}

Termos para indexação: Sulcador, precisão de semeadura, Zea mays L.

\section{ABSTRACT}

An experiment was carried out at UFLA Agricultural Department, in order to technically evaluate three no-tillage seederfertilizers on clayey typical Dystroferric Red Latosol (LVdf). Seeders S1 - Semeato SHM 11/13, S2 and S3 - John Deere RT 907 with different furrow opening systems were utilized at three different speeds $\left(5,0 ; 6,5 ; 8,0 \mathrm{~km}^{-1}\right)$. Quantified variables were: stand plants $\mathrm{m}^{-1}$; plant emergence speed; sowing uniformity (double, acceptable, failure); sowing depth; mechanical damages, and seed germination. A randomized block design in shared fragments was employed. Sowing uniformity to S1 and S2 (analogous systems to straw cutting and fertilizer opening) showed no significant differences. Pneumatic system showed no economical benefits, considering the high investment, when compared to the mechanical system with horizontal disks in corn culture. Speed increase reduced sowing uniformity (double, acceptable, failure), besides increasing mechanical seed damage.

Index terms: Opener, precision in sowing, maize, crop.

(Recebido em 9 de novembro de 2006 e aprovado em 23 de abril de 2007)

\section{INTRODUÇÃO}

Os sistemas de cultivo podem ser classificados em três grupos distintos: sistema convencional, no qual o solo é preparado e a sua superfície fica totalmente exposta; cultivo mínimo, qualquer sistema de cultivo com menor movimentação de solo e trânsito de máquinas em relação ao usualmente adotado numa determinada região que deixe o máximo de cobertura vegetal, e plantio direto, no qual a deposição das sementes é feita diretamente no solo, sem haver nenhum preparo prévio.

Derpsch et al. (1991) definem plantio direto como sistema de plantio na qual a semente é depositada diretamente no solo minimamente preparado, onde os resíduos da cultura anterior permanecem na superfície e as plantas daninhas são controladas quimicamente. Comparado com outros métodos de preparo, é o único em que a energia de impacto das gotas de chuva é amortecida pela camada de cobertura morta e a erosão é controlada eficazmente.

Segundo Derpsch (1985) o plantio direto é um processo de semeadura em solo minimamente preparado, no qual as sementes são colocadas em sulcos ou covas, com largura e profundidade suficientes para se obter uma adequada cobertura e um adequado contato da semente com o solo. Caracteriza-se pela menor intensidade de mobilização e redução do tráfego de máquinas.

\footnotetext{
${ }^{1}$ Parte da dissertação de Mestrado do primeiro autor.

${ }^{2}$ Mestre em Engenharia Agrícola, Professor - Departamento de Engenharia Rural - Escola Agrotécnnica Federal de Codó/EAF - Povoado Poraquê, s/n - Zona Rural -65400-000 - Codó, MA - aristonps@yahoo.com.br

${ }^{3}$ Doutora em Fitotecnia, Professora - Departamento de Engenharia/DEG - Universidade Federal de Lavras/UFLA - Cx. P. 3037 - $37200-000$ - Lavras, MG - mcctouri@ufla.br

${ }^{4}$ Doutor em Engenharia Agrícola, Professor - Departamento de Engenharia/DEG - Universidade Federal de Lavras/UFLA - Cx. P. 3037 - $37200-000$ Lavras, MG - volpato@ufla.br
} 
A semeadora é o equipamento mais importante para o sucesso do plantio direto. Além da distribuição uniforme das sementes e sua colocação adequada no sulco para garantir a germinação, a semeadora sob plantio direto desempenha as funções de cortar a palha e romper o solo na linha de semeadura. Segundo Tourino (1986), a precisão na distribuição de sementes significa sua localização exata no sulco, segundo espaçamentos e quantidades regulares predeterminadas. Afirma, ainda, que a distribuição de sementes ao longo de uma fileira de semeadura, bem como a exata colocação do adubo, seja qual for o sistema adotado, são alguns dos aspectos mais importantes a serem considerados em relação às causas de baixas produtividades. Segundo Kurachi et al. (1986) e Tourino et al. (2002), estudos apontam a uniformidade de distribuição longitudinal de sementes como uma das características que mais contribuem para um estande adequado de plantas e, consequientemente, para a melhoria da produtividade da cultura.

De acordo com Fey et al. (2000), o aumento da velocidade na operação de semeadura de milho influenciou a uniformidade de distribuição longitudinal de plantas, más não afetou a população e a produtividade de grãos. Segundo Dambrós (1998), o aumento da velocidade reduziu a uniformidade de distribuição de plantas. Silva et al. (2000), avaliaram o sistema de plantio direto de milho por 12 anos, utilizando uma semeadora de discos horizontais perfurados, variando as velocidades de deslocamento de 3,0;6,0; 9,0 e $11,2 \mathrm{~km} \mathrm{~h}^{-1} \mathrm{e}$ as profundidades de deposição de fertilizantes de 5 e $10 \mathrm{~cm}$, concluíram que o número de plantas na linha de semeadura foi reduzido com o aumento da velocidade.

Portella et al. (1997), avaliando semeadoras em plantio direto, não encontraram diferenças significativas no índice de emergência de plantas de milho, em função dos elementos sulcadores e compactadores. Entretanto, em solos com baixo teor de água, com elemento sulcador tipo facão, as sementes foram distribuídas com maior profundidade do que com discos duplos. Em solos mais úmidos, ocorreu o contrário, com problemas de embuchamento e aderência de solo ao facão.

Segundo Razera (1979), a porcentagem de sementes quebradas pelos mecanismos dosadores, na cultura da soja, é influenciada pela velocidade de deslocamento da semeadora. A porcentagem de sementes quebradas aumentou em $13 \%$, quando a velocidade de deslocamento aumentou de 4,0 $\mathrm{km} \mathrm{h}^{-1}$ para $8,0 \mathrm{~km} \mathrm{~h}^{-1}$. Esta quebra ocorre em função do aumento da velocidade angular do disco dosador, causando maiores danos mecânicos nas sementes pelos choques, interferências e abrasões, contra o nivelador, nas bordas dos orifícios dos discos.
De acordo com Silva et al. (1993), o sucesso no desenvolvimento de uma cultura, bem como sua produtividade, depende, em parte, do ambiente do solo em torno da semente, na ocasião da semeadura. Os principais fatores físicos desse ambiente, -temperatura, umidade e aeração, são diretamente influenciados pelas condições encontradas, pelo tipo de solo e pela profundidade de semeadura.

Casão Júnior et al. (1998) e Portella et al. (1997) afirmam que sulcadores do tipo facão possuem ângulo de ataque para facilitar sua penetração no solo, evitando a necessidade de transferência total de peso da máquina na penetração dos discos de corte dos resíduos e dos discos de distribuição das sementes no solo, facilitando um preparo localizado com uma profundidade estabilizada entre 8 a $15 \mathrm{~cm}$ na deposição do fertilizante.

Assim, objetivou-se com esta pesquisa estudar as interações máquina-solo-planta, investigando e avaliando as características de distribuição de sementes de três semeadoras adubadoras de precisão com diferentes mecanismos de abertura de sulco no sistema de plantio direto de milho. Avaliou-se o estande de plantas por metro, o índice de velocidade de emergência de plantas; uniformidade de semeadura (duplos, aceitáveis, falhas), profundidade de semeadura, danos mecânicos e germinação das sementes.

\section{MATERIAL E MÉTODOS}

O trabalho foi conduzido no campo experimental do Departamento de Engenharia da Universidade Federal de Lavras (UFLA), situado no município de Lavras, MG, com localização geográfica definida entre as coordenadas

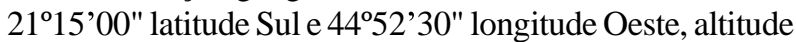
média de 918,8 metros, declividade média de $8 \%$ e exposição face Sul. Caracterizado climaticamente por temperatura média anual normal de $19,4^{\circ} \mathrm{C}$ e precipitação total anual normal de $1530 \mathrm{~mm}$, concentrada, principalmente, no período de outubro a março (clima classificado como Cwa.). O solo foi classificado como sendo Latossolo Vermelho Distroférrico típico argiloso (LVdf). A área vem sendo utilizada desde a safra 2002/2003 com semeadura direta de milho e, em 2004, com semeadura direta de feijão. Foi utilizado como fonte de tração um trator Valtra 900L 4 x 2 TDA, potência nominal de $90 \mathrm{cv}$, a $2270 \mathrm{rpm}$. A dessecação foi realizada com Glyphosate (Roundup Original), utilizando um pulverizador de barras, marca Jacto, com 20 bicos, espaçado de 0,50 m. As máquinas utilizadas foram: S1 semeadora-adubadora de precisão semeato SHM 11/13, com 4 linhas espaçadas de $70 \mathrm{~cm}$, com disco liso de corte de palha e sulcador tipo guilhotina para fertilizantes e 
sulcadores de discos duplos defasados para sementes, mecanismo dosador do tipo discos horizontais com furos, rodas reguladoras de profundidade na parte posterior e rodas compactadoras em "V" (Figura 1a); S2 - semeadoraadubadora de precisão John Deere RT 907 VacuMeter"M $^{\mathrm{TM}}$ com 4 linhas espaçadas de $70 \mathrm{~cm}$, disco duplo defasado para corte de palha e sulco de fertilizante, disco duplo defasado para sementes, mecanismo dosador pneumático a vácuo, rodas reguladoras de profundidade laterais aos discos duplos de sementes, rodas de compactação em "V" (Figura 1b) e S3 - a mesma semeadora S2, com as seguintes alteração: disco de corte de palha liso e sulcador do tipo haste para sulco de fertilizante e disco duplo defasado para sementes (Figura 1c).

O experimento foi constituído de 27 subparcelas, formadas por tratamentos compostos de três semeadoras, três velocidades de deslocamento e três repetições. As velocidades utilizadas foram V1 $\left(5,0 \mathrm{~km} \mathrm{~h}^{-1}\right), \mathrm{V} 2\left(6,5 \mathrm{~km} \mathrm{~h}^{-1}\right)$ e V3 $\left(8,0 \mathrm{~km} \mathrm{~h}^{-1}\right)$. Ambas as semeadoras foram reguladas para uma densidade meta de 6 plantas $\mathrm{m}^{-1}$. O delineamento experimental foi em blocos ao acaso, com três repetições e nove tratamentos dispostos em parcelas subdivididas. Nas parcelas foram dispostas as semeadoras e, nas subparcelas, as velocidades.

Cada parcela e subparcela com área de $63 \mathrm{~m}^{2} \mathrm{e}$ dimensões de $30 \mathrm{~m}$ x 2,10 m e espaçadas entre si de $10 \mathrm{~m}$ e entre blocos de $2 \mathrm{~m}$, as parcelas e subparcelas foram constituídas por quatro linhas de semeadura espaçadas de $70 \mathrm{~cm}$, sendo as duas linhas externas consideradas como bordadura e as duas linhas internas consideradas como área útil. A semente utilizada foi a cultivar GNZ 2005 hibrido triplo modificado, grãos do tipo semi-duro alaranjado, ciclo precoce, florescimento 55-60 dias, plantio de verão e safrinha, resistente ao acamamento, densidade: safra 55.000 a 60.000 plantas ha ${ }^{-1}$; safrinha 50.000 a 55.000 plantas ha-1. Os discos utilizados foram: na semeadora S1, $n^{\circ} .03$ AGROPLAST com 28 furos, encontrados no comércio local. Nas semeadoras S2 e S3, nº A 50617 PVC rígido Standard com 30 furos. A quantidade de sementes por metro na linha de plantio foi calculada considerando-se: para as três semeadoras - Germinação de $80 \%$ e Pureza de $98 \%$; para a semeadora S1 - Dano mecânico de 5\% e Deslizamento de rodas de 5\%; para as semeadoras S2 e S3 - Dano mecânico de 0\% e deslizamento de rodas de $10 \%$.

A determinação do índice de velocidade de emergência foi realizada por meio da contagem diária das plântulas emergidas em um metro, nas duas linhas centrais das subparcelas, iniciando-se logo após a emergência da primeira plântula que ocorreu cinco dias após a semeadura, estendendo-se até o décimo quarto dia, quando cessou a emergência. $\mathrm{O}$ número de plântulas emergidas nos dias após a semeadura e o índice de velocidade de emergência das plântulas foi analisado seguindo classificação adaptada de Popinigis (1985). Para a avaliação da uniformidade, os espaçamentos entre plantas (Xi) foram medidos com uma trena de $50 \mathrm{~m}$ esticada rente ao solo e as plantas nas duas linhas centrais de semeadura, medindose 250 plantas consecutivas, após o décimo quarto dia da semeadura. Os dados foram analisados, conforme a ABNT (1994) para a avaliação de espaçamentos entre sementes, determinando-se o porcentual de espaçamentos correspondentes às classes: aceitáveis $(0,5 \mathrm{X}$ ref $\leq \mathrm{Xi}<1,5$ $\mathrm{X}$ ref), duplos ( $\mathrm{Xi}<0,5 \mathrm{X}$ ref) e falhos ( $\mathrm{Xi} \geq 1,5 \mathrm{X}$ ref), em que $X$ ref é o espaçamento de referência. No experimento, $\mathrm{X}$ ref foi de $8,33 \mathrm{~cm}$ para as três semeadoras. Dessa forma, os espaçamentos entre plantas foram classificados como
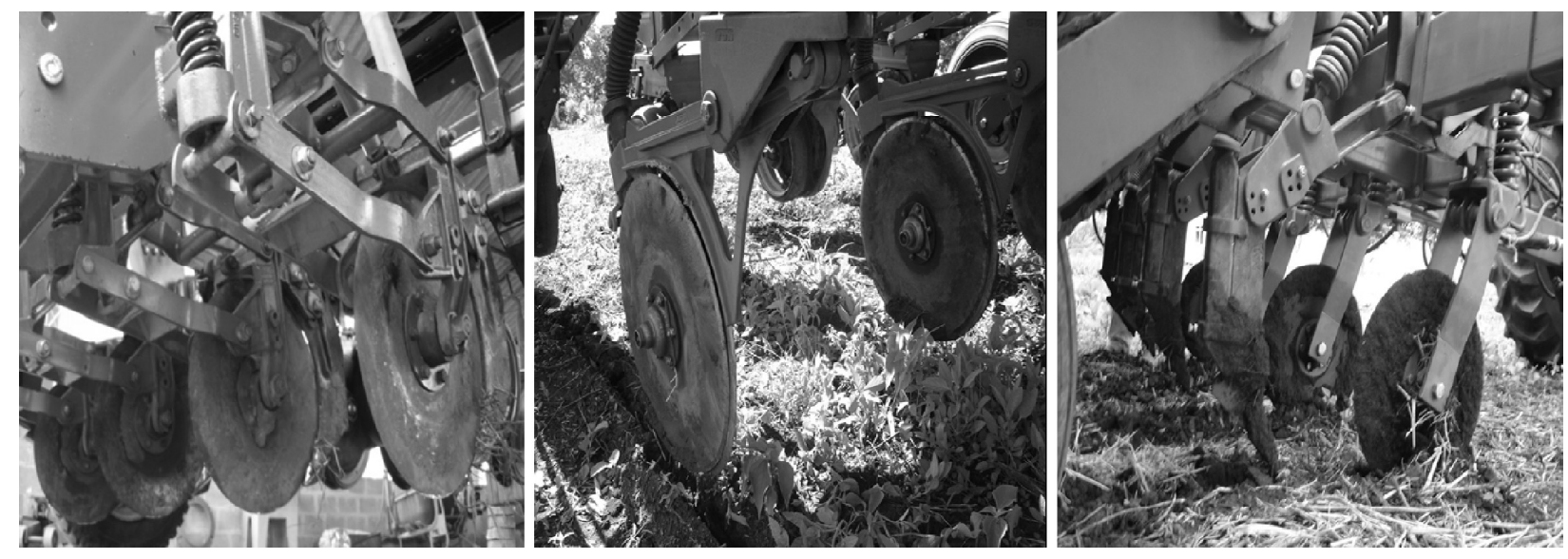

Figura 1 - Detalhes dos mecanismos de abertura do sulco para deposição do adubo. 
aceitáveis $(4,17 \mathrm{~cm} \leq \mathrm{Xi}<12,50 \mathrm{~cm})$, duplos $(\mathrm{Xi}<4,17 \mathrm{~cm})$ e falhos $(\mathrm{Xi} \geq 12,50 \mathrm{~cm})$.

Os dados de profundidade de semeadura foram coletados logo após o plantio em um metro linear nas duas linhas centrais de semeadura e escavando ate descobrir as sementes foi medida a profundidade de 10 sementes uma a uma utilizando uma régua com graduação em centímetros. Os dados foram submetidos a analise estatística através do teste de Tukey a $1 \%$ e $5 \%$ para comparar os contrastes entre as médias e apresentadas nas Tabelas 1 e 3 .

Para a análise de germinação e danos mecânicos, foram coletadas 200 sementes para testemunha e 400 para as demais análises, semeadoras e velocidades, num total de 28 amostras. A coleta da testemunha foi feita diretamente no saco de sementes e, das demais, em área de teste ao lado da área já semeada, simulando-se as semeaduras. Os tubos de distribuição de sementes das duas linhas centrais das semeadoras foram vedados com fita crepe e marcados em suas partes médias para a coleta de 200 sementes de cada um deles. As sementes foram misturadas, somandose um total de 400 sementes, embaladas e registradas com as denominações das semeadoras, velocidades e repetições. Os testes foram feitos no Laboratório de Análise de Sementes da UFLA, conforme recomendações da Regra de Análise de Sementes (BRASIL, 1992). Os testes de germinação foram feitos com quatro repetições de cinqüenta sementes em cada tratamento e os resultados foram submetidos à análise estatística. Os testes de danos mecânicos foram feitos com duas repetições de cem sementes em cada tratamento. Os resultados foram transformados pela raiz quadrada de $\mathrm{Y}$ para a realização das análises estatísticas através do teste de Tukey a $1 \%$ e $5 \%$ e, para a apresentação nas Tabelas 2 e 3, foram destransformados.

\section{RESULTADOS E DISCUSSÃO}

Os resultados obtidos na análise de variância para estande (plantas $\mathrm{m}^{-1}$ ), índice de velocidade de emergência, uniformidade de distribuição de plantas (duplos, aceitáveis e falhas) e profundidade de semeadura encontram-se na Tabela 1. Na Tabela 2 são apresentados os resultados obtidos na análise de variância para danos mecânicos e germinação e, na Tabela 3, são apresentados os resultados de médias obtidos para estande (plantas $\mathrm{m}^{-1}$ ), índice de velocidade de emergência, uniformidade de distribuição de plantas (duplos, aceitáveis e falhas), profundidade de semeadura, danos mecânicos e germinação. Pelos resultados da análise de variância (Tabelas 1 e 2) observase que o fator semeadora foi significativo para estande (plantas $\mathrm{m}^{-1}$ ) e uniformidade (duplos e falhas), enquanto que, o fator velocidade afetou significativamente somente a uniformidade de espaçamentos (duplos, aceitáveis e falhas) e os danos mecânicos. Observa-se ainda uma interação significativa entre os fatores velocidade e semeadoras para estande, espaçamentos duplos, danos mecânicos e germinação.

Analisando-se as médias dos tratamentos, mostrados na Tabela 3, para semeadoras, observa-se que

Tabela 1 - Resumo da análise de variância (QM), para plantas $\mathrm{m}^{-1}(\mathrm{Pm})$, índice de velocidade de emergência (IVE), duplos (D), aceitáveis (A), falhas (F) e profundidade de semeadura (PS). ${ }^{(1)}$

\begin{tabular}{lclccccc}
\hline \multicolumn{1}{c}{ F. V. } & GL & Pm & IVE & D & A & F & PS \\
\hline Semeadora & 2 & $1,37^{*}$ & $0,22 \mathrm{~ns}$ & $183,26^{* *}$ & $12,35 \mathrm{~ns}$ & $515,15^{* *}$ & $0,70 \mathrm{~ns}$ \\
Repetição & 2 & $0,26 \mathrm{~ns}$ & $0,03 \mathrm{~ns}$ & $9,59 \mathrm{~ns}$ & $7,70 \mathrm{~ns}$ & $32,93 \mathrm{~ns}$ & $0,60 \mathrm{~ns}$ \\
\hline Erro 1 & 4 & 0,15 & 0,07 & 1,76 & 4,15 & 4,93 & 1,54 \\
Velocidade & 2 & $0,15 \mathrm{~ns}$ & $0,034 \mathrm{~ns}$ & $18,82^{* *}$ & $306,26^{* *}$ & $173,37^{* *}$ & $0,15 \mathrm{~ns}$ \\
V * S & 4 & $0,37^{*}$ & $0,091 \mathrm{~ns}$ & $17,48^{* *}$ & $37,7 \mathrm{~ns}$ & $20,37 \mathrm{~ns}$ & $0,26 \mathrm{~ns}$ \\
Erro 2 & 12 & 0,074 & 0,05 & 2,15 & 12,56 & 9,54 & 0,222 \\
\hline Total corrigido & 26 & & & & & \\
\hline CV 1 (\%) & 7,12 & & 13,29 & 13,51 & 2,80 & 12,62 & 22,62 \\
CV 2 (\%) & 5,03 & & 11,33 & 14,93 & 4,88 & 17,55 & 8,6 \\
\hline Média Geral & 5,41 & & 1,94 & 9,815 & 72,63 & 175,93 & 5,48 \\
\hline
\end{tabular}

(1) Na análise de variância, "ns" representam ausência de significância. Os valores significativos são indicados como (**) e $(*)$, para $1 \%$ e $5 \%$, respectivamente. 
Tabela 2 - Resumo da análise de variância (QM), para os danos mecânicos (DM) e germinação $(\mathrm{G}) .{ }^{(1)}$

\begin{tabular}{lcccc}
\hline \multirow{2}{*}{ Fonte de variação } & \multicolumn{2}{c}{ Danos Mecânicos } & Germinação \\
\cline { 2 - 5 } & G.L. & QM & G.L. & QM \\
\hline Semeadora & 2 & $1,300 \mathrm{~ns}$ & 2 & $3,111 \mathrm{~ns}$ \\
Repetição & 1 & $0,164 \mathrm{~ns}$ & 3 & $22,963 \mathrm{~ns}$ \\
Erro 1 & 2 & 0,192 & 6 & 13,185 \\
Velocidade & 2 & $2,213 * *$ & 2 & $5,444 \mathrm{~ns}$ \\
Velocidade * semeadora & 4 & $0,518^{*}$ & 4 & $19,778^{*}$ \\
Erro 2 & 6 & 0,067 & 18 & 6,556 \\
\hline Total corrigido & 17 & & 35 & 3,75 \\
\hline Coeficiente de variação 1 & 13,48 & & 2,65 & \\
Coeficiente de variação 2 & 7,00 & & 96,778 & \\
\hline Média Geral & 10,555 & & \\
\hline
\end{tabular}

(1) $\mathrm{Na}$ análise de variância "ns" representam ausência de significância, os valores significativos são indicados como $(* *)$ e $(*)$, para $1 \%$ e $5 \%$, respectivamente.

Tabela 3 - Médias de plantas $\mathrm{m}^{-1}(\mathrm{Pm})$, índice de velocidade de emergência IVE(\%), duplos $\mathrm{D}(\%)$, aceitáveis $\mathrm{A}(\%)$, falhas $\mathrm{F}(\%)$, profundidade de semeadura PS $(\mathrm{cm})$, danos mecânicos $\mathrm{DM}(\%)$ e germinação $\mathrm{G}(\%)$. $^{(1)}$

\begin{tabular}{|c|c|c|c|c|c|c|c|c|}
\hline Tratamento & $\mathrm{Pm}$ & IVE & $\mathrm{D}$ & A & $\mathrm{F}$ & PS & $\mathrm{DM}$ & $\mathrm{G}$ \\
\hline \multicolumn{9}{|l|}{ Semeadora } \\
\hline $\mathrm{S} 1$ & $5,8 b$ & $2,0 \mathrm{a}$ & $7,7 \mathrm{a}$ & $80,9 b$ & $11,3 \mathrm{a}$ & $5,4 a$ & $11,5 \mathrm{a}$ & $96,3 a$ \\
\hline $\mathrm{S} 2$ & $5,0 \mathrm{a}$ & $1,8 \mathrm{a}$ & $15,0 \mathrm{~b}$ & $59,2 \mathrm{a}$ & $26,0 \mathrm{c}$ & $5,8 \mathrm{a}$ & $13,1 \mathrm{a}$ & $96,7 \mathrm{a}$ \\
\hline $\mathrm{S} 3$ & $5,4 \mathrm{ab}$ & $2,1 \mathrm{a}$ & $6,8 \mathrm{a}$ & $77,8 \mathrm{~b}$ & $15,4 b$ & $5,2 \mathrm{a}$ & $7,4 \mathrm{a}$ & $97,3 \mathrm{a}$ \\
\hline \multicolumn{9}{|l|}{ Velocidade } \\
\hline V1 & $5,6 \mathrm{a}$ & $2,0 \mathrm{a}$ & $8,3 a$ & $78,4 \mathrm{c}$ & $13,2 \mathrm{a}$ & $5,6 a$ & $8,1 \mathrm{a}$ & $97,2 \mathrm{a}$ \\
\hline $\mathrm{V} 2$ & $5,3 \mathrm{a}$ & $1,9 \mathrm{a}$ & $9,9 \mathrm{ab}$ & $72,7 b$ & $17,6 \mathrm{~b}$ & $5,3 \mathrm{a}$ & $8,8 \mathrm{a}$ & $97,2 \mathrm{a}$ \\
\hline V3 & $5,3 \mathrm{a}$ & $1,9 \mathrm{a}$ & $11,2 \mathrm{~b}$ & $66,8 \mathrm{a}$ & $22,0 \mathrm{c}$ & $5,6 a$ & $15,6 \mathrm{~b}$ & $96,0 \mathrm{a}$ \\
\hline Média geral & 5,4 & 1,9 & 9,8 & 72,6 & 17,6 & 5,5 & 10,6 & 96,8 \\
\hline & \multicolumn{8}{|c|}{ Desdobramento } \\
\hline \multicolumn{9}{|c|}{ Velocidade d. semeadora $\mathrm{S} 1$} \\
\hline V1 & $5,7 \mathrm{a}$ & $1,9 \mathrm{a}$ & $6,3 a$ & $84,7 \mathrm{a}$ & $8,7 \mathrm{a}$ & $5,3 \mathrm{a}$ & $7,0 \mathrm{a}$ & $95,5 a$ \\
\hline $\mathrm{V} 2$ & $5,7 \mathrm{a}$ & $1,8 \mathrm{a}$ & $7,7 \mathrm{a}$ & $79,3 \mathrm{a}$ & $13,0 \mathrm{a}$ & $5,3 \mathrm{a}$ & $8,4 \mathrm{a}$ & $96,5 a$ \\
\hline V3 & $6,0 \mathrm{a}$ & $2,1 \mathrm{a}$ & $9,0 \mathrm{a}$ & $78,7 \mathrm{a}$ & $12,3 \mathrm{a}$ & $5,7 \mathrm{a}$ & $21,5 b$ & $97,0 \mathrm{a}$ \\
\hline \multicolumn{9}{|c|}{ Velocidade d. semeadora S2 } \\
\hline V1 & $5,0 \mathrm{a}$ & $1,8 \mathrm{a}$ & $10,7 \mathrm{a}$ & $68,7 \mathrm{c}$ & $21,3 \mathrm{a}$ & $5,7 \mathrm{a}$ & $9,3 \mathrm{a}$ & $99,0 \mathrm{~b}$ \\
\hline $\mathrm{V} 2$ & $5,0 \mathrm{a}$ & $1,9 \mathrm{a}$ & $16,7 b$ & $58,7 \mathrm{~b}$ & $24,7 \mathrm{a}$ & $5,7 \mathrm{a}$ & $12,5 \mathrm{ab}$ & $98,0 \mathrm{~b}$ \\
\hline V3 & $5,0 \mathrm{a}$ & $1,6 a$ & $17,7 \mathrm{~b}$ & $50,3 \mathrm{a}$ & $32,0 \mathrm{~b}$ & $6,0 \mathrm{a}$ & $18,4 \mathrm{~b}$ & $93,0 \mathrm{a}$ \\
\hline \multicolumn{9}{|c|}{ Velocidade d. semeadora S3 } \\
\hline V1 & $6,0 \mathrm{~b}$ & $2,3 a$ & $8,0 \mathrm{a}$ & $82,0 \mathrm{~b}$ & $9,7 \mathrm{a}$ & $5,7 \mathrm{a}$ & $8,0 \mathrm{a}$ & $97,0 \mathrm{a}$ \\
\hline $\mathrm{V} 2$ & $5,3 \mathrm{a}$ & $2,1 \mathrm{a}$ & $5,3 a$ & $80,0 \mathrm{~b}$ & $15,0 \mathrm{ab}$ & $5,0 \mathrm{a}$ & $6,0 \mathrm{a}$ & $97,0 \mathrm{a}$ \\
\hline V3 & $5,0 \mathrm{a}$ & $1,9 \mathrm{a}$ & $7,0 \mathrm{a}$ & $71,3 \mathrm{a}$ & $21,7 \mathrm{~b}$ & $5,0 \mathrm{a}$ & $8,5 \mathrm{a}$ & $98,0 \mathrm{a}$ \\
\hline
\end{tabular}

${ }^{(1)}$ Médias seguidas de mesma letra não diferem entre si, a $1 \%$ e $5 \%$ de probabilidade, pelo teste de Tukey. 
a semeadora $\mathrm{S} 1$ apresentou tendência de melhores resultados em estande $\left(5,8\right.$ plantas $\left.\mathrm{m}^{-1}\right)$ e uniformidade de espaçamentos aceitáveis $(80,9 \%)$ com menor percentual de falhas $(11,3 \%)$ do que as demais semeadoras S2 e S3. As diferenças, entretanto, para estande, duplos e aceitáveis, entre as semeadoras S1 e S3, não foram significativas.

A semeadora $\mathrm{S} 1$, com $80,9 \%$, analisada segundo os critérios sugeridos por Coelho (1996), com índice de espaçamentos aceitáveis acima de $60 \%$ (para semeadoras de discos horizontais com furos), e pelos critérios sugeridos por Tourino \& Klingensteiner (1983) com índice de espaçamentos aceitáveis acima de $75 \%$, teve um padrão bom de desempenho.

A semeadora S3 com 77,8\%, não atingiu o índice de espaçamentos aceitáveis de $90 \%$ (para semeadoras pneumáticas), sugerido por Coelho (1996), Considerandose esses fatores e a não ocorrência de diferenças significativas entre os mesmos, pode-se afirmar que na semeadura do milho a semeadora S1 de discos horizontais com furos demonstrou a mesma eficiência na singularização das sementes que a semeadora S3 de sistema pneumático.

A semeadora S2 de sistema pneumático com 59,2\% de índice de espaçamentos aceitáveis, $15,0 \%$ de duplos e $26,0 \%$ de falhos apresentou diferenças significativas inferior para aceitáveis e superiores para duplos e falhos em relação às demais semeadoras S1 e S3. Esses fatores ocorreram influenciados pelo tipo diferenciado do mecanismo de disco duplo defasado para corte de palha e sulco de fertilizante utilizado na semeadora S2, diferente dos tipos de mecanismos utilizados para o corte de palha e sulco de fertilizantes das demais semeadoras S1 e S3.

Entre as três semeadoras, não houve diferenças significativas entre si nos tratamentos índice de velocidade de emergência, profundidade de semeadura e germinação.

Entre as três velocidades de deslocamento, não houve diferenças significativas entre si nos tratamentos estande plantas $\mathrm{m}^{-1}$, índice de velocidade de emergência, profundidade de semeadura e germinação. As velocidades V1 e V2 não apresentaram diferenças significativas entre si nos tratamentos duplos e danos mecânicos, mas, em relação à velocidade V3, apresentaram menores índices significativos de danos mecânicos $8,1 \%$ e $8,8 \%$ respectivamente.

A velocidade $\mathrm{V} 1$ com relação às demais velocidades $\mathrm{V} 2$ e V3 foi a que apresentou diferenças significativamente maiores para espaçamentos aceitáveis $78,4 \%$ e menores para espaçamentos duplos $8,3 \%$ e falhos $13,2 \%$. Demonstrando estatisticamente que com o aumento da velocidade ocorreu uma redução na qualidade da semeadura, observando-se um aumento significativo nos índices de duplos e de falhas. Padrões de precisão semelhante também foram encontrados por Fey et al. (2000), Mercante et al. (2005) e Silva et al. (2000). A uniformidade na semeadura é considerada, por Kurachi et al. (1986), Tourino (1986) e Tourino et al. (2002), como um fator que influencia na melhoria da produtividade da cultura. Para Fey et al. (2000), entretanto, os resultados obtidos não afetaram a produtividade do milho.

Como constatado na analise de variância, para estande, duplos, danos mecânicos e germinação o aumento da velocidade não apresentou o mesmo comportamento em cada semeadora. As semeadoras S1 e S2 não foram afetadas significativamente na variável estande plantas $\mathrm{m}^{-}$ ${ }^{1}$ com o aumento da velocidade. A semeadora S1 mantevese próxima e atingiu o estande meta de 6 plantas $\mathrm{m}^{-1} \mathrm{com}$ o aumento da velocidade. Por outro lado, a semeadora S2 apresentou os menores valores de estande 5 plantas $\mathrm{m}^{-1}$, isso ocorreu, em consequiência do elevado índice de danos mecânicos, os quais cresceram significativamente de 9,3\% para $18,4 \%$ resultando proporcionalmente num elevado índice de falhas crescente de $21,3 \%$ para $32,0 \%$ com o aumento da velocidade. A semeadora $\mathrm{S} 1$ também foi afetada com o aumento da velocidade, em relação aos danos mecânicos às sementes, os quais apresentaram um crescimento passando de 7,0\% para $21,5 \%$. A semeadora $\mathrm{S} 3$ apresentou menor profundidade de semeadura, danos mecânicos e duplos, e maior germinação, sem sofrer variações significativas nesses fatores com o aumento da velocidade, más, foi afetada significativamente, decrescendo o estande meta de 6 plantas $\mathrm{m}^{-1}$ em V1 para 5 plantas $\mathrm{m}^{-1} \mathrm{em} \mathrm{V3}$ por causa da ocorrência significativa de alto índice de falho e baixo índice de aceitáveis, não singularizando adequadamente as sementes com o aumento da velocidade.

Constatou-se na analise de variância que, tanto entre as três semeadoras quanto entre as três velocidades de deslocamento, não houve diferenças significativas entre si nos tratamentos índice de velocidade de emergência, profundidade de semeadura e germinação. $\mathrm{O}$ mesmo ocorreu com o aumento da velocidade dentro das três semeadoras, com exceção para a variável germinação na semeadora S2 que apresentou um baixo índice significativo na germinação por causa do aumento significativo dos danos mecânicos com o aumento da velocidade.

\section{CONCLUSÕES}

1) O sistema pneumático não apresentou vantagem econômica (considerando-se o alto investimento) em relação ao sistema mecânico de discos horizontais, na implantação da cultura do milho; 2) Analisando-se as 
semeadoras com sistema pneumático, concluiu-se que, a alteração do sistema de corte de palha e abertura dos sulcos de fertilizantes da semeadora S2 para transformá-la na semeadora S3 melhorou significativamente o desempenho da semeadora; 3) O aumento da velocidade de deslocamento reduziu a uniformidade de semeadura e aumentou os danos mecânicos nas sementes; 4) $\mathrm{O}$ aumento da velocidade de deslocamento para $8,0 \mathrm{~km} \mathrm{~h}^{-1}$ aumentou significativamente os danos mecânicos as sementes nas semeadoras S1 e S2, apesar de possuírem sistema dosadores de sementes diferentes, enquanto que na semeadora S3 não houve alteração significativa nesse parâmetro.

\section{REFERÊNCIAS BIBLIOGRÁFICAS}

ASSOCIAÇÃO BRASILEIRA DE NORMAS TÉCNICAS. Projeto de norma 04.015.06-004 semeadoras de precisão: ensaio de laboratório: método de ensaio. Rio de Janeiro, 1994. $26 \mathrm{p}$.

BRASIL. Ministério da Agricultura e Reforma Agrária. Secretaria Nacional de Defesa Agropecuária. Regras para análise de sementes. Brasília, DF, 1992. 365 p.

CASÃO JÚNIOR, R.; ARAÚJO, A. G.; RALISCH, R.; SILVA, A. L.; LADEIRA, A. S.; SILVA, J. C.; MACHADO, P.; ROSSETO, R. Avaliação do desempenho da semeadoraadubadora Magnum 2850 PD no basalto paranaense. Circular do Instituto de Agronomia do Paraná, Londrina, n. 105, p. 1-47, 1998.

COELHO, J. L. D. Ensaio e certificação das máquinas para a semeadura. In: MIALHE, L. G. Máquinas agrícolas: ensaios \& certificação. Piracicaba: FEALQ, 1996. p. 551-570.

DAMBRÓS, R. M. Avaliação do desempenho de semeadoras-adubadoras de milho com diferentes mecanismos dosadores. 1998. 86 f. Dissertação (Mestrado em Máquinas Agrícolas) - Escola Superior de Agricultura Luiz de Queiróz, Piracicaba, 1998.

DERPSCH, R. Histórico, requisitos, importância e outras considerações sobre plantio direto no Brasil. In:

O plantio direto no Brasil. Campinas: Fundação Cargill, 1985. p. 1-11.

DERPSCH, R.; ROTH, C. H.; SIDIRAS, N.; KOPKE, U. Controle da erosão no Paraná, Brasil: sistemas de cobertura do solo, plantio direto e preparo conservacionista do solo.
Eschborn: GTZ, 1991. 272 p.

FEY, E.; SANTOS, S. R.; FEY, A. Influência da velocidade de semeadura sobre a produtividade de milho (Zea mays L.). In: CONGRESSO BRASILEIRO DE ENGENHARIA AGRÍCOLA, 29., 2000, Fortaleza. Anais... Fortaleza: SBEA, 2000. CD-ROM.

KURACHI, S. A. H.; SILVEIRA, G. M.; COSTA, J. A.; MORAES, R. A. D. M.; BERNARDI, J. A.; MOREIRA, C. A.; PETRONI, A. C.; SILVA, J. R.; MESQUITA, C. M. Código de avaliação de semeadoras e/ou adubadoras. Campinas: IAC, 1986. v. 3, 138 p. (Documentos).

MERCANTE, E.; SILVA, S. de L.; MODOLO, A. J.; SILVEIRA, J. C. M. da. Demanda energética e distribuição de sementes de milho em função da velocidade de duas semeadoras. Revista Brasileira de Engenharia Agrícola e Ambiental, Campina Grande, v. 9, n. 3, p. 424-428, jul./set. 2005.

POPINIGIS, F. Fisiologia da semente. 2. ed. Brasília, DF: Agiplan, 1985. 289 p.

PORTELLA, J. A.; SATLER, A.; FAGANELLO, A. Índice de emergência de plântulas de soja e de milho em semeadura direta no Sul do Brasil. Engenharia Agrícola, Jaboticabal, v. 17, n. 1, p. 71-78, set. 1997.

RAZERA, L. F. Efeitos de danificações mecânicas causadas por semeadoras em sementes de soja. 1979. $67 \mathrm{f}$. Dissertação (Mestrado em Fitotecnia) - Escola Superior de Agricultura Luiz de Queirós, Piracicaba, 1979.

SILVA, F. M.; COAN, O.; NATALE, W. Influência da profundidade de semeadura com e sem uso de sulcador na cultura de milho (Zea mays L.). In: CONGRESSO BRASILEIRO DE ENGENHARIA AGRÍCOLA, 22., 1993, Ilhéus. Anais... Ilhéus: SBEA/CEPLAC, 1993. p. 14381452 .

SILVA, S. de L.; BENEZ, S. H.; RICIERI, R. P.; PEREIRA, J. O. Demanda energética em sistema de semeadura direta em milho. In: CONGRESSO BRASILEIRO DE ENGENHARIA AGRÍCOLA, 29., 2000, Fortaleza. Anais... Fortaleza: SBEA, 2000. CD-ROM.

TOURINO, M. C. C. A semente no lugar certo. A Granja, Porto Alegre, v. 42, n. 461, p. 36-40, jun. 1986. 
TOURINO, M. C. C.; KLINGENSTEINER, P. Ensaio e avaliação de semeadoras Adubadoras. In: CONGRESSO BRASILEIRO DE ENGENHARIA AGRÍCOLA, 13., 1983, Seropédica. Anais... Seropédica: SBEA, 1983. p. 103-107.
TOURINO, M. C. C.; REZENDE, P. M.; SALVADOR, N. Espaçamento, densidade e uniformidade de semeadura na produtividade e características agronômicas da soja. Pesquisa Agropecuária Brasileira, Brasília, v. 37, n. 8, p. 1071-1077, ago. 2002. 